\title{
Title: The risk-return trade-off in Europe: A temporal and cross-sectional analysis
}

Vicent Aragón $^{\mathrm{a}, *}$ and Enrique Salvador ${ }^{\mathrm{a}, 1}$

${ }^{\mathrm{a}}$ Finance and Accounting Department, Universitat Jaime I

Avenida Sos Baynat s/n, E-12071 Castellón de la Plana, Spain

* Corresponding author. Tel: +34 964 727134; Fax: +34 964 728565;

E-mail address: arago@cofin.uji.es

\section{Abstract}

This paper analyzes the risk-return trade-off in European equities considering both temporal and cross-sectional dimensions. In our analysis, we introduce not only the market portfolio but also 15 industry portfolios comprising the entire market. Several bivariate GARCH models are estimated to obtain the covariance matrix between excess market returns and the industrial portfolios and the existence of a risk-return trade-off is analyzed through a cross-sectional approach using the information in all portfolios. It is obtained evidence for a positive and significant risk-return trade-off in the European market. This conclusion is robust for different GARCH specifications and is even more evident after controlling for the main financial crisis during the sample period.

Keywords: Equity risk premium, multivariate GARCH, cross-sectional analysis, ICAPM, risk aversion

JEL classification: G01, G12, G15

\footnotetext{
${ }^{1}$ This author is grateful to the Universitat Jaume I for support through the Research Personnel Training program (PREDOC/2007/12). The authors are grateful for financial assistance from the Fundació Caixa Castelló-Bancaixa. (P11B2006-16)
} 


\section{The risk-return trade-off in Europe: A temporal and cross-sectional analysis}

\section{Introduction}

In his seminal paper, Merton (1973) shows that exists a positive relationship between the conditional mean on the wealth portfolio, $E_{t}\left[r_{M, t}-r_{f, t}\right]$. to its conditional variance, $\sigma_{M, t}^{2}$, and its conditional covariance with the investment opportunity set $\sigma_{M F, t}$.

$$
E_{t}\left[r_{M, t}-r_{f, t}\right]=\left[\frac{-J_{W W} W}{J_{W}}\right] \sigma_{M, t}^{2}+\left[\frac{-J_{W F}}{J_{W}}\right] \sigma_{M F, t}
$$

Where $\mathrm{J}$ is the indirect utility function depending on wealth $\mathrm{W}(\mathrm{t})$ (subscripts represents partial derivatives) and any variables $\mathrm{F}(\mathrm{t})$ denoting the stochastic investment opportunity set. The first term between brackets is related to the risk aversion coefficient, and the second term in brackets to the adjustment to the variables representing the stochastic opportunity set.

Despite the important role of this trade-off in the financial literature, there is no clear consensus about its empirical evidence. In a theoretical framework, all the parameters (the risk prices in brackets) and the variables (the sources of risk) are allowed to be time varying. However, to make this model empirically tractable one must make several assumptions; the most common is that of constant risk prices (Goyal and Santa-Clara (2003), Bali et al. (2005)). Another common assumption made in the empirical analysis of the risk-return trade-off is that of a set of investment opportunities constant over time, leaving the market risk as the only source of risk in the ICAPM (Baillie and De Gennaro (1990), Glosten et al. (1993)). Finally, the empirical model is established in a discrete time economy instead of the continuous time economy used in the equilibrium model of the theoretical approach.

Then, the most used approach in the empirical literature is the following univariate model:

$$
E_{t}\left[r_{M, t}-r_{f, t}\right]=C+A \sigma_{M, t}^{2}+e_{t}
$$

The general model reduces to this restricted version if one assumes that the investment opportunity set is time invariant or if the representative market participant has log utility. While both assumptions are likely 
extreme (particularly when focusing on time-varying volatility), Merton (1980) argues that the general intertemporal equilibrium risk return tradeoff can still be “'reasonably approximated”' by Eq. (2), and this is certainly the specification that much of the literature has employed (see Lundblad (2007) for a review). The methodology used in most of the papers analyzing empirically the model in (2) is based in the GARCH-M framework developed by Engle et. el (1987). Most of the studies using this GARCH-M approach have focused on the implications of this relationship to a single data series representing the market portfolio. These studies propose different models to describe the volatility processes (GARCH family (e.g. Guo and Neely (2008)) and MIDAS (e.g. Ghysels et, al (2005), Leon et. al (2007)) and several proxies to be used as excess market returns. However, the evidence obtained is controversial. In recent years, Bali (2008) and Bali and Engle (2010) suggest that the empirical tests of the Merton model has been focused narrowly on the market index. These authors analyze this relationship considering not only the time series dimension but also by imposing a cross-sectional consistency to a set of portfolios and equities representing the entire market. Using this methodology, these authors were able to confirm a positive risk-return relationship.

Our study contributes to this line of research in three aspects: (1) applying this approach to European data, (2) showing that an exclusive analysis using the market index can lead to non-significant estimates of the risk aversion coefficient, and (3) the result of a positive and significant risk-return trade-off is robust to the covariance matrix specification and it is more evident when we condition the empirical model to the main financial crisis occurred in the sample period.

The paper is structured as follows: section 2 describes the data and methodology. Section 3 discusses the main results obtained and section 4 provides a summary.

\section{Data and methodology}


The data of this study consists of 1130 weekly $^{1}$ excess returns from January 1988 to August 2009 for the whole European market and 15 industrial indexes. Excess returns for the market portfolio are calculated using the log-returns of the Eurostoxx index subtracting the proxy for the risk-free ${ }^{2}$ investment.

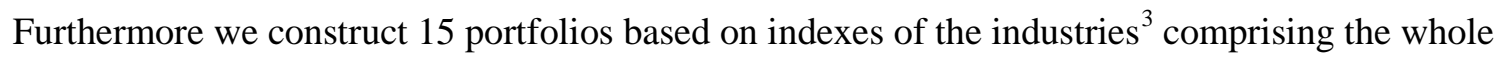

European market. These industries are: Automobiles, Banks, Basic Resources, Chemicals, Construction, Energy, Financial Services, Food and Beverage, Health and Care, Industrial, Insurance, Media,

Technology, Telecommunications and Utilities. We calculated excess industry returns in the same way that we did for the market portfolio. The index data are obtained from Datastream and the risk free rates from International Financial Statistics.

Following equation 2, we estimate the risk return relation using this equation system (Bali (2008) and Bali and Engle (2010)):

$$
R_{i, t+1}=C_{i}+A \sigma_{i m, t+1}+e_{i, t+1}
$$

where $i=1,2, \ldots . n$ are the industrial portfolios, $R_{i, t+1}$ are the returns of the $i^{\text {th }}$ portfolio, $e_{i, t+1}$ represents the disturbance of the $i^{\text {th }}$ equation and $\sigma_{i m, t+1}$ represents the covariance between the market portfolio and the $i^{\text {th }}$ portfolio. Previously to estimate this equation system, we must obtain the covariances $\sigma_{i m, t+1}$ for all portfolios. We use several bivariate GARCH specifications. The mean equation is defined as:

$$
\begin{aligned}
& R_{i, t+1}=a_{0, i}+a_{1, i} R_{i, t}+e_{i, t+1} \\
& R_{m, t+1}=a_{0, m}+a_{1, m} R_{m, t}+e_{m, t+1}
\end{aligned}
$$

\footnotetext{
${ }^{1}$ Following papers such as Capiello and Fearnley (2000) or Ghysels et al. (2007), we analyze this relationship using weekly data rather the monthly data used in other studies Even though there are slight differences in the parameter estimations using different data frequency, there is no particular reason that the conclusions in this study should be affected by the selection of data frequency. Some authors point out this fact in their studies (Lundblad 2007).

${ }^{2}$ Following Leon et. al (2007) we use an average of the monthly compounded market money rates in France, Spain, Germany, United Kingdom and Italy as proxy for the risk-free rate or return.

${ }^{3}$ The main reason of using portfolios instead of stocks is to reduce the dimensionality of the estimation. Moreover, the industrial indexes have a lower idiosyncratic risk than stocks.
} 
$\left(\begin{array}{l}e_{i, t+1} \\ e_{m, t+1}\end{array}\right)=e_{t+1} \sim B N\left(0, H_{t+1}\right)$

while we propose three different models for the variance equation. The first is the BEKK model of Baba et. al (1990)

$$
H_{t+1}=\left(\begin{array}{cc}
\sigma_{i, t+1}^{2} & \sigma_{i m, t+1} \\
\sigma_{i m, t+1} & \sigma_{m, t+1}^{2}
\end{array}\right)=C C^{\prime}+\alpha e_{t} e_{t}^{\prime} \alpha+\beta H_{t} \beta
$$

where $a_{0, i}, \quad a_{0, m}, a_{1, i}, \quad a_{1, m}$, are parameters and $C, \quad \alpha, \quad \beta$ are 2x2 matrixes of parameters to estimate.

In the second model we consider the asymmetric response of volatility to shocks of different sign using a bivariate GJR specification of Glosten et. al (1993).

$$
H_{t+1}=\left(\begin{array}{cc}
\sigma_{i, t+1}^{2} & \sigma_{i m, t+1} \\
\sigma_{i m, t+1} & \sigma_{m, t+1}^{2}
\end{array}\right)=C C^{\prime}+\alpha e_{t} e_{t}^{\prime} \alpha+\beta H_{t} \beta+D \eta_{t} \eta_{t} D
$$

where $D$ is a $2 x 2$ matrix of parameters to estimate and $\eta_{t}=\min \left(0, e_{t}\right)$

The last specification uses the Dynamic Conditional Correlation (DCC) model of Engle (2002). In this case, the variance equation is defined as:

$$
H_{t+1}=\left(\begin{array}{cc}
\sigma_{i, t+1}^{2} & \sigma_{i m, t+1} \\
\sigma_{i m, t+1} & \sigma_{m, t+1}^{2}
\end{array}\right)=D_{t} R_{t} D_{t} \quad \text { where } \quad D_{t}=\left(\begin{array}{cc}
\sqrt{\sigma_{i, t+1}^{2}} & 0 \\
0 & \sqrt{\sigma_{m, t+1}^{2}}
\end{array}\right)
$$

and $R_{t}=\operatorname{diag}\left\{Q_{t}^{-1}\right\} Q_{t} \operatorname{diag}\left\{Q_{t}^{-1}\right\} \quad$ and $Q_{t}=S(1-\alpha-\beta)+\alpha\left(e_{t-1} e_{t-1}\right)+\beta Q_{t-1}$

being $\mathrm{S}$ the unconditional correlation of the innovations, and $\sigma_{M, t}^{2}, \sigma_{M, t}^{2}$ are defined as univariate GARCH processes. 
The parameters in all models are estimated by maximizing the quasi-maximum likelihood function of Bollerslev-Wooldridge (1992) under normality assumption ${ }^{4}$.

$$
L(\theta)=\sum_{t=1}^{T} \ln \left[f\left(r_{t}, \Omega_{t} ; \theta\right)\right] \text { where } f\left(r_{t}, \Omega_{t} ; \theta\right)=(2 \pi)^{-1}\left|H_{t}\right|^{-\frac{1}{2}} \exp \left(-\frac{1}{2} \varepsilon_{t}^{T} H_{t}^{-1} \varepsilon_{t}\right)
$$

Table 1 shows the descriptive statistics for the estimated conditional covariances of excess market returns and excess industry returns ${ }^{5}$.

\section{[INSERT TABLE 1]}

With these conditional covariances, we estimate in a second stage the 15 equations of the system defined in equation (2) simultaneously constraining the risk aversion coefficient to be the same in all equations (Bali, 2008) for cross-sectional consistency that allows us expanding the analysis of the intertemporal relation to a large cross section of stock portfolios and also expanding the cross-sectional analysis to each conditional time step based on bivariate-GARCH estimates. We estimate this system of equations using a Seemingly Unrelated Regression (SUR) method that allows us to place constraints on coefficients ${ }^{6}$.

\section{Empirical results}

The main results of our study are presented in table 2 . For robustness, we analyze not only the full sample period but also control for two major financial crises during the 1988-2009 period ${ }^{7}$. Panel A shows the results for the risk-return relationship focused exclusively on the European market portfolio represented by the Eurostoxx index. This GARCH-M methodology (Bollerslev et. al (1988)) fails to estimate a significant risk aversion parameter for all cases. These results are similar to those obtained by Baillie and De Gennaro (1990) and Glosten et. al (1993) using this methodology.

\section{[INSERT TABLE 2]}

\footnotetext{
${ }^{4}$ The QML estimations are obtained using the BFGS optimization algorithm in the MATLAB optimization routines.

${ }^{5}$ For brevity, we only present the results for the BEKK specification. The results for the other specification vary slightly. Results available upon request.

${ }^{6}$ The SUR estimations are obtained using the STATA econometrics software

${ }^{7}$ These include the subprime crisis of October 2007-2009 and the 2000-2002 crises following the bursting of the tech bubble. We control for the crises periods using dummy variables. These two periods are the most important financial crises periods during the sample period according to the European Commission. Source: http://ec.europa.eu/economy_finance/publications/cycle_indicators/index_en.htm
} 
Panels B , C and D present the estimations for the alternative methodology proposed using the 15 portfolios representing the entire European market for each alternative covariance specification. For all GARCH specifications we obtain a significant positive risk aversion parameter. Moreover, after controlling for financial crisis periods we observe an increase in the risk aversion parameter obtaining similar values than other studies for US market (Bali (2008)).This last result could reflect an interesting fact reported in early studies such as Mayfield (2004) and Lettau, Ludvigson (2003) Kim and Lee (2008). In these studies the risk return tradeoff is less pronounced during documented recessions, consistent with declining levels of risk aversion during recessions (reduction of parameter A). Therefore, after controlling for these well-documented recession periods, we do obtain an increase of the risk-aversion level as it is suggested by these authors. The results in this section allow us to conclude that by extending the risk return relationship along both time series and cross-sectional dimensions can lead to significant positive trade-off. Despite the different GARCH specification used in the covariance matrix, we can obtain a positive and significant risk-return trade-off when we used the two stages temporal and cross-sectional analysis.

Finally, we show in Figure 1 the risk premium evolution during the last two decades in Europe ${ }^{8}$. The periods coinciding with the crisis periods considered above (dot-com bubble and last global financial crisis) are the periods with a higher risk premium demanded by European investors due basically with the extremely increase of the non-diversifiable risk. The average of the weekly risk premiums series shows that over the past 20 years the risk premium in Europe has remained at approximately 3,5\% per annum, varying slightly with the model specification.

\section{[INSERT FIGURE 1]}

Summing up, the non-significant estimates of the risk aversion parameter obtained when we focus narrowly on the market index are essentially due to the low statistical power of the GARCH-M

\footnotetext{
${ }^{8}$ For the sake of brevity we only show the risk Premium for the BEKK specification. The differences between specifications are negligible. Results are available upon request.
} 
methodology (Lundblad, 2007). However, if we consider temporal and cross-sectional dimensions simultaneously we increase the statistical power of our estimations by pooling data along the two dimensions. This paper supports a favorable evidence of this methodology in different markets than USA, where other studies have focused (e.g. Bali and Engle (2010)).

\section{Conclusion}

This paper analyzes the risk return trade-off in European equity markets using a methodology that allows us to consider both temporal and cross-sectional dimensions. We can estimate a positive and significant relationship between return and risk using this methodology but we obtain no favorable evidence when we focus narrowly in a single portfolio. These findings support earlier studies which found evidence of the risk-return trade-off for U.S. data. The results obtained are robust to several specifications of the covariance matrix and the considerations of the main financial crisis in the sample reinforce the existence of a positive and significant risk-return trade-off.

\section{References}

Baillie, R. T., and De Gennaro, R.P., 1990. Stock returns and volatility, Journal of Financial and Quantitative Analysis, 25, 203-214.

Baba, Y., Engle, R. F., Kraft, D. F., Kroner, K. F. 1990. Multivariate simultaneous generalized ARCH, Unpublished Working Paper, mimeo, University of California at San Diego.

Bali, T. G., 2008. The intertemporal relation between expected return and risk, Journal of Financial Economics, 87, 101-131.

Bali, T.G., Cakici, N., Yan, X., Zhang, Z., 2005. Does idiosyncratic risk really matter? Journal of Finance, 60, 905-929.

Bali, T. G., Engle R., F., 2010. The Intertemporal Capital Asset Pricing Model with Dynamic Conditional Correlations, Journal of Monetary Economics, 57(4), 377-390

Bollerslev, T., Engle, R.F., Wooldridge, J.M., 1988. A capital asset pricing model with time-varying covariances. Journal of Political Economy, 96, 116-131.

Bollerslev, T., Wooldridge, J., 1992. Quasi-maximum likelihood estimation and inference in dynamic models with time-varying covariances. Econometric Reviews, 11, 143-172.

Capiello, L. and Fearnley, T.A., 2000. International CAPM with Regime-Switching Parameters. FAME Research Paper Series, rp17, International Center for Financial Asset Management and Engineering. 
Engle, R., 2002. Dynamic Conditional Correlation: A Simple Class of Multivariate Generalized Autoregressive Conditional Heteroskedasticity Models. Journal of Business \& Economic Statistics, 20, 339-350

Engle, R. F., Lilien, D. M., and Robins, R. P., 1987. Estimating Time Varying Risk Premia in the Term Structure: The Arch-M Model. Econometrica, 55, pp. 391-407.,

Ghysels, E., Santa-Clara, P., Valkanov, R., 2005. There is a risk-return trade-off after all. Journal of Financial Economics, 76, 509-548.

Ghysels, E., Sinko, A., Valkanov, R., 2007. 'MIDAS Regressions: Further Results and New Directions', Econometric Reviews, 26, 53-90

Goyal, A., Santa-Clara, P. ,2003. Idiosyncratic risk matters! Journal of Finance 58, 975-1008.

Glosten, L. R., Jagannathan, R., Runkle D. E., 1993. On the relation between the expected value and the variance of the nominal excess return on stocks, Journal of Finance, 48, 1779-1801.

Guo, H., Neely, C. J., 2008. Investigating the intertemporal risk-return relation in the international stock markets with the component GARCH model, Economics letters, 99, 371-374.

Kim, S. W., and B. S. Lee, 2008. Stock Returns, Asymmetric Volatility, Risk Aversion, and Business Cycle: Some New Evidence. Economic Inquiry, 46, 131-148.

León, A., Nave, J. Rubio, G., 2007. The relationship between risk and expected return in Europe, Journal of Banking and Finance, 31, 495-512

Lettau, M., and Ludvigson, S., 2003. Measuring and modeling variation in the risk return trade-off. Working paper, New York University.

Lundblad, C., 2007. The risk-return trade-off in the long run: 1836-2003, Journal of Financial Economics, 85, 123-150.

Mayfield, S., 2004. Estimating the market risk premium. Journal of Financial Economics, 73, 867-887.

Merton, R. C., 1973. An intertemporal asset pricing model, Econometrica, 41, 867-888.

Merton, R.C.,1980. On Estimating the Expected Return on the Market: An Exploratory Investigation, Journal of Financial Economics, 8, 323-361. 
TABLE 1. Descriptive statistics of estimated covariances

\begin{tabular}{|l|c|c|c|c|c|}
\hline \multicolumn{1}{|c|}{ Industry } & Average & Median & Std & Min & Max \\
\hline Automobiles & 8.2515 & 5.2773 & 8.9224 & 1.9294 & 62.8422 \\
\hline Banks & 7.7269 & 4.3620 & 10.8540 & 1.3278 & 104.1552 \\
\hline Basic Resources & 7.7296 & 4.0597 & 13.8395 & -3.4400 & 161.1576 \\
\hline Chemicals & 6.5634 & 9.2296 & 9.2296 & -0.3920 & 103.1669 \\
\hline Construction & 6.7891 & 8.4140 & 1.4293 & 1.4293 & 91.0249 \\
\hline Energy & 5.9923 & 3.4020 & 10.3220 & -0.8391 & 115.2223 \\
\hline Financial Services & 7.2763 & 3.9081 & 11.2140 & -0.2050 & 101.1505 \\
\hline Food and Beverage & 4.4290 & 2.9154 & 6.4617 & -6.5830 & 70.5070 \\
\hline Health and Care & 5.1454 & 3.2404 & 7.2480 & 0.5843 & 84.6600 \\
\hline Industrial & 6.9994 & 4.4709 & 8.0590 & 1.5898 & 80.7440 \\
\hline Insurance & 8.7740 & 4.8838 & 12.0281 & 1.3248 & 108.1796 \\
\hline Media & 6.5957 & 4.0099 & 7.6795 & 1.1153 & 80.0576 \\
\hline Technology & 8.8597 & 5.0689 & 8.8453 & 1.5682 & 68.4209 \\
\hline Telecommunications & 7.0536 & 4.7057 & 8.6013 & 0.9753 & 103.5855 \\
\hline Utilities & 5.6302 & 3.4890 & 8.4792 & 1.1579 & 89.9963 \\
\hline
\end{tabular}

This table reports the summary statistics (sample average, median, standard deviation, minimum and Maximum values) of the corresponding conditional covariances (multiplied by 10E4) between the excess weekly returns of the market portfolio and the 15 industry portfolios. 
TABLE 2. - Estimated parameters

\begin{tabular}{|c|c|c|}
\hline \multicolumn{3}{|c|}{ Panel A .- Risk return relation on the market index } \\
\hline Sample period & C & A \\
\hline Full sample: Jan 1988-Aug 2009 & $\begin{array}{l}6.190 \cdot 10 \mathrm{E}-4 \\
(0.80)\end{array}$ & $\begin{array}{l}1.692 \\
(1.25)\end{array}$ \\
\hline $\begin{array}{l}\text { Full sample: Jan 1988-Aug } 2009 \text { and controlling } \\
\text { for crisis 2007-2009 }\end{array}$ & $\begin{array}{l}-9.245 \cdot 10 \mathrm{E}-5 \\
\quad-(0.945)\end{array}$ & $\begin{array}{c}2.1075 \\
(0.9935)\end{array}$ \\
\hline $\begin{array}{l}\text { Full sample: Jan 1988-Aug } 2009 \text { and controlling } \\
\text { for crises 2000-2002 and 2007-2009 }\end{array}$ & $\begin{array}{l}-8.434 \cdot 10 \mathrm{E}-4 \\
-(0.5987)\end{array}$ & $\begin{array}{c}4.213 \\
(1.6887)\end{array}$ \\
\hline \multicolumn{3}{|c|}{ Panel B .- Risk return relation with cross-sectional consistency (BEKK) } \\
\hline Sample period & $\bar{C}^{9}$ & A \\
\hline Full sample: Jan 1988-Aug 2009 & $\begin{array}{l}-5.694 \cdot 10 \mathrm{E}-4 \\
(-0.52)\end{array}$ & $\begin{array}{l}0.859 \\
(1.96)\end{array}$ \\
\hline $\begin{array}{l}\text { Full sample: Jan 1988-Aug } 2009 \text { and controlling } \\
\text { for crisis 2007-2009 }\end{array}$ & $\begin{array}{c}-7.763 \cdot 10 \mathrm{E}-4 \\
(-0.71)\end{array}$ & $\begin{array}{l}1.413 \\
(2.08)\end{array}$ \\
\hline $\begin{array}{l}\text { Full sample: Jan 1988-Aug } 2009 \text { and controlling } \\
\text { for crises 2000-2002 and 2007-2009 }\end{array}$ & $\begin{array}{c}-1.183 \cdot 10 \mathrm{E}-3 \\
(-0.80) \\
\end{array}$ & $\begin{array}{l}3.392 \\
(3.11)\end{array}$ \\
\hline \multicolumn{3}{|c|}{ Panel C .- Risk return relation with cross-sectional consistency (GJR-BEKK) } \\
\hline Sample period & $\bar{C}$ & A \\
\hline Full sample: Jan 1988-Aug 2009 & $\begin{array}{l}3.259 \cdot 10 \mathrm{E}-3 \\
(0.30)\end{array}$ & $\begin{array}{l}0.942 \\
(2.33)\end{array}$ \\
\hline $\begin{array}{c}\text { Full sample: Jan 1988-Aug } 2009 \text { and controlling } \\
\text { for crisis 2007-2009 }\end{array}$ & $\begin{array}{l}3.707 \cdot 10 \mathrm{E}-3 \\
(0.27)\end{array}$ & $\begin{array}{l}3.763 \\
(7.42) \\
\end{array}$ \\
\hline $\begin{array}{l}\text { Full sample: Jan 1988-Aug } 2009 \text { and controlling } \\
\text { for crises 2000-2002 and 2007-2009 }\end{array}$ & $\begin{array}{l}3.831 \mathrm{E}-3 \\
(0.266)\end{array}$ & $\begin{array}{l}6.0783 \\
(10.85) \\
\end{array}$ \\
\hline \multicolumn{3}{|c|}{ Panel C .- Risk return relation with cross-sectional consistency (DCC) } \\
\hline Sample period & $\bar{C}$ & A \\
\hline Full sample: Jan 1988-Aug 2009 & $\begin{array}{l}-5.467 \cdot 10 \mathrm{E}-3 \\
(-0.54)\end{array}$ & $\begin{array}{l}0.886 \\
(2.03)\end{array}$ \\
\hline $\begin{array}{l}\text { Full sample: Jan 1988-Aug } 2009 \text { and controlling } \\
\text { for crisis 2007-2009 }\end{array}$ & $\begin{array}{c}-5.805 \cdot 10 \mathrm{E}-3 \\
(-0.5761)\end{array}$ & $\begin{array}{l}3.574 \\
(7.46)\end{array}$ \\
\hline $\begin{array}{l}\text { Full sample: Jan 1988-Aug } 2009 \text { and controlling } \\
\text { for crises 2000-2002 and 2007-2009 }\end{array}$ & $\begin{array}{c}-5.646 \cdot 10 \mathrm{E}-3 \\
(-0.561)\end{array}$ & $\begin{array}{c}5.285 \\
(10.52)\end{array}$ \\
\hline
\end{tabular}

This table shows the estimated coefficients for the models presented above (t-stats in parentheses). Panel A shows the results for a GARCH-M model which considered only the excess return for the European market portfolio (Eurostoxx index). Panel B shows the results for the model which consider the entire market through the 15 portfolios based on the industrial index (and constraining for cross-sectional consistency). For the sake of brevity, we only show the constant $\mathrm{C}$ average of all portfolios as the whole market constant $\mathrm{C}$ (and the average t-stat in parentheses

\footnotetext{
${ }^{9}$ The individual estimated parameters vary between the lowest value of -0.00205 obtained for the Insurance sector in the BEKK specification and the highest 0.00021 value for the Health and Care sector also in the BEKK covariance matrix, but there is not a significant parameter in any case analyzed. We just present the average parameter and t-stat (as in Bali (2008)) in order to save space.
} 
FIGURE 1.- Risk premium evolution in Europe

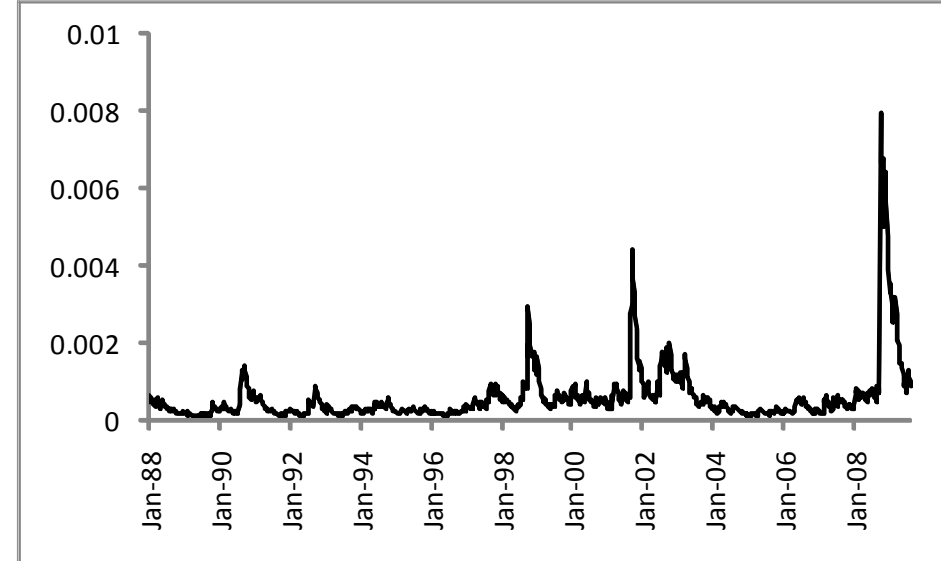

This figure represents the weekly risk premium evolution in Europe from 1 January 1988 to 31 August 2009 